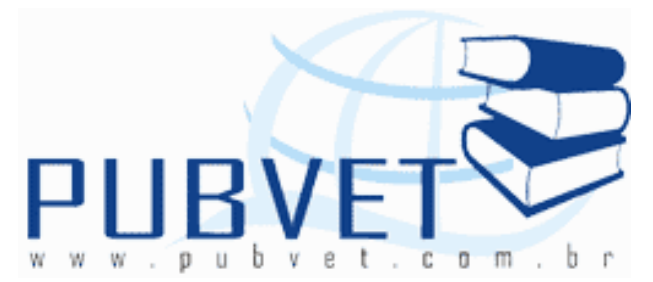

PUBVET, Publicações em Medicina Veterinária e Zootecnia.

\title{
Produção de leite e intervalo entre partos de um rebanho de vacas mestiças no Norte do Piauí
}

Eduardo Esmeraldo Augusto Bezerra ${ }^{1}$, João Avelar Magalhães ${ }^{2}$, Danielle Maria Machado Ribeiro Azevêdo², Ricardo Gomes de Araújo Pereira ${ }^{3}$, Cláudio Ramalho Townsend ${ }^{3}$, Newton de Lucena Costa ${ }^{4}$

${ }^{1}$ Médico Veterinário, M.Sc., Ematerpi. Parnaíba, Piauí.

${ }^{2}$ Médico Veterinário, D.Sc., Embrapa Meio-Norte. Parnaíba, Piauí.

3ZZootecnista, D.Sc., Embrapa Rondônia.

${ }^{4}$ Engenheiro Agrônomo, M.Sc., Embrapa Roraima. Doutorando em Agronomia/Produção Vegetal, UFPR. Curitiba, Paraná.

\section{Resumo}

Estudou-se o intervalo entre partos (IEP), produção de leite/lactação, duração da lactação e produção de leite/vaca/dia/lactação em 199 lactações de vacas mestiças, entre a 1a e 6a lactação, oriundas da Fazenda Várzea, localizada no município de Buriti dos Lopes - Piauí. Foram considerados os registros coletados no período de 2000 a 2002. As medias de intervalo entre partos, período de lactação, produção de leite/vaca/dia e produção de leite/vaca/lactação foram, respectivamente, 13,01 meses, 286,5 dias, 14,31 $\mathrm{kg}, 4.513 \mathrm{~kg}$.

Termos para indexação: bovinos de leite, produção leiteira, baixo Parnaíba 
BEZERRA, E.E.A. et al. Produção de leite e intervalo entre partos de um rebanho de vacas mestiças no Norte do Piauí. PUBVET, Londrina, V. 5, N. 1, Ed. 148, Art. 992, 2011.

\section{Milk production and calving interval of crossbred cows in Piauí State}

\section{Abstract}

It was studied the calving interval (CI), production of milk lactation, duration of the lactation, production of milk/cow/day lactation, among calving in 199 lactation of crossbred cows, among to $1 \mathrm{a}$ and 6 a lactation, originating from of Fazenda Várzea, located in the county district of Buriti of Lopes - Piauí. The registrations collected in the period from 2000 to 2002 were considered. The parturition interval and lactation period, milk/cow/day production and milk/cow/lactation production were, respectively, 13,01 months, 286,5 days, $14,31 \mathrm{~kg}, 4.513 \mathrm{~kg}$.

Index terms: Dairy cows, milk production, low Parnaíba river

\section{Introdução}

O leite e seus derivados constituem importante fonte de proteína, cálcio e fósforo, podendo assumir papel decisivo na tarefa de erradicar a fome e assegurar o direito à alimentação de qualidade à população de baixa renda.

No Piauí, a produtividade dos rebanhos leiteiros é muito baixa, baseada principalmente em pequenos produtores que, muitas vezes por questões econômicas ou mesmo culturais, manejam inadequadamente seus rebanhos, diminuindo a eficiência produtiva e reprodutiva. A maioria desses rebanhos provém de animais mestiços oriundos de cruzamentos não bem definidos. Segundo Santos (1999), alguns dos requisitos básicos para melhoraria dos coeficientes de produtividades é 0 uso de tecnologias simples como inseminação artificial, pastagens cultivadas, desmame precoce, suplementação alimentar, escrituração zootécnica, manejo sanitário e melhoramento genético. Por outro lado, o estresse térmico e a qualidade dos alimentos da região, têm inviabilizado o uso de animais puros. Entretanto, alguns produtores de leite do Nordeste, quando adotam alguma tecnologia, alcançam índices elevados de produção de leite com a utilização de animais mestiços, principalmente os oriundos do cruzamento de raças européias (produção) com raças zebuínas 
BEZERRA, E.E.A. et al. Produção de leite e intervalo entre partos de um rebanho de vacas mestiças no Norte do Piauí. PUBVET, Londrina, V. 5, N. 1, Ed. 148, Art. 992, 2011.

(rusticidade) (ALCOFORADO, et al., 2000). Durães e Freitas (2000) relataram que, nos últimos anos, a produção de leite e o período de lactação dos rebanhos de vacas mestiças aumentaram consideravelmente.

O objetivo desse trabalho foi estudar as características produtivas de um rebanho de vacas mestiças nas condições edafoclimáticas do norte do Piauí.

\section{Material e Métodos}

Os dados utilizados neste trabalho foram obtidos na Fazenda Várzea (305' Latitude sul e $41^{\circ} 41^{\prime}$ de longitude oeste), localizada no município de Buriti dos Lopes, Piauí. Foram considerados os registros coletados no período de 2000 a 2002, referentes 199 lactações de vacas mestiças Holandês x Zebu $(1 / 2,3 / 4$ e $7 / 8)$, entre a 1 a e 6 a lactação.

O clima da região, segundo Köppen é Aw, com estação seca bem definida (julho a dezembro) pluviosidade média anual de $1.300 \mathrm{~mm}$. A média das temperaturas máximas é de $36^{\circ} \mathrm{C}$ enquanto que a das mínimas é de $22^{\circ} \mathrm{C}$. O solo da fazenda é do tipo Neossolo Flúvico eutrófico.

Os animais foram mantidos em pastagens de canarana lisa (Echinochloa pyramidalis), com suplementação de $1 \mathrm{~kg}$ de ração para cada $3 \mathrm{~kg}$ de leite produzido, além de $5 \mathrm{~kg}$ de cana+uréia por animal em lactação. O período de pastejo foi de 1 dia, com 28 dias de descanso. As áreas de pastagem eram adubadas com 240 de N/ha/ano, na forma de uréia, e irrigadas por inundação.

O manejo reprodutivo foi realizado com inseminação artificial, utilizando sêmen de touros holandeses e gir leiteiro e reprodutores dessas raças nos repasses. As novilhas foram cobertas com aproximadamente 17 meses, quando atingiam $330 \mathrm{~kg}$ de peso vivo. As ordenhas eram realizadas mecanicamente, pela manhã e à tarde. O manejo sanitário constou de vacinas (aftosa e brucelose), IBR. BVD e leptospirose, botulismo, raiva, enterotoxemia), CMT, controle de ecto e endoparasitos. Os parâmetros avaliados foram intervalo entre parto (IEP), período de lactação, produção de leite/vaca/dia e produção de leite/vaca/lactação. 
BEZERRA, E.E.A. et al. Produção de leite e intervalo entre partos de um rebanho de vacas mestiças no Norte do Piauí. PUBVET, Londrina, V. 5, N. 1, Ed. 148, Art. 992, 2011.

\section{Resultados e Discussão}

As boas condições de manejo nutricional e reprodutivo em que os animais são criados permitiram a obtenção de índices zootécnicos elevados, aproximando-se dos observados em outras regiões do país onde, tradicionalmente, exploram essa atividade. A média de IEP (13,01 meses) ficou próxima do ideal (12 meses), bem inferior aos 18 meses da média brasileira (VETROMILA, 2000). Conforme GAVA (1987), o sucesso da atividade leiteira está diretamente relacionado com intervalo entre dois partos.

A média de duração da lactação, obtida no período em estudo, foi $286,5+52,97$ dias, aproximando-se aos relatados por Silva Netto et al. (2001) em Rondônia, com animais holando-zebu alimentados em pastagens tropicais e suplementação de acordo com a produção de leite. Entretanto, são superiores à observada por Reyes et al. (2001), no México, em animais Holandês x Pardo Suíço x Zebu mantidos em pastagens de Cynodon sp e Panicum maximun e concentrado.

A média de produção de leite por vaca/dia/lactação e vaca/lactação foi de $14,31+3,19$ e $4.132,61+1.163,22 \mathrm{~kg}$, respectivamente. Esses resultados são semelhantes aos obtidos na região Sudeste do Brasil (FERREIRA; MADALENA, 1997) e superiores aos observados em animais holando-zebu mantidos em pastagens tropicais, em Goiás (VIANA, 1988), na Amazônia (MENDONÇA et al., 1990), no sul da Bahia (SANTANA e PEREIRA, 1998), na região do Brejo, Paraíba (ALCOFORADO et al., 2000) e Quixeramobim, Ceará (XIMENES, 2009). Porém, são inferiores à média de $4.513,66 \mathrm{~kg}$ de leite/vaca/lactação, descritos por Freitas et al. (2001), em vacas mestiças holando-zebu, com graus de sangue variados, em diversas fazendas de Minas Gerais. 
BEZERRA, E.E.A. et al. Produção de leite e intervalo entre partos de um rebanho de vacas mestiças no Norte do Piauí. PUBVET, Londrina, V. 5, N. 1, Ed. 148, Art. 992, 2011.

\section{Conclusões}

As medias de intervalo entre partos, período de lactação, produção de leite/vaca/dia e produção de leite/vaca/lactação foram, respectivamente, 13,01 meses, 286,5 dias, $14,31 \mathrm{~kg}, 4.513 \mathrm{~kg}$, demonstrando que, com o uso de tecnologia e manejo adequados, existe possibilidade de sucesso no agronegócio leite na região norte do Piauí.

\section{Referências Bibliográficas}

ALCOFORADO, C.A. de A.T.; EVANGELISTA, A. et al. Dados de produção de leite de um rebanho mestiço na região do Brejo Paraibano. In: CONGRESSO NORDESTINO DE PRODUÇÃO ANIMAL, 2, Teresina, Piauí. Anais... Teresina: SNPA. 2000, pg 134-136.

DURÃES, M. C.; FREITAS, A. F. Cruzamento de raças aponta resultados eficazes. Balde Branco, v.36, n.433, p.56-59, 2000.

FERREIRA, J.J.; MADALENA, F.E. Efeito do sistema de cruzamento sobre o desempenho produtivo e reprodutivo de vacas leiteiras. Arquivo Brasileiro de Medicina Veterinária e Zootecnia, v.49, n.6, p.741-752, 1997.

FREITAS, M.S.; DURÃES, M.C.; FREITAS, A.F. et al. Comparação da produção de leite e de gordura e da duração da lactação entre cinco "graus de sangue" originados de cruzamentos entre Holandês e Gir em Minas Gerais. Arquivo Brasileiro de Medicina Veterinária e Zootecnia, v.53, n.6, p.708-713, 2001.

GAVA, D. Mais leite? Diminua o intervalo entre partos. Noticiário Tortuga, v.33, n.353, 1987.

MENDONÇA, J.F.B.; MAGALHÃES, J.A.; COSTA, N. de L. Sistema físico de produção de leite de vacas holansozebu em pastagens tropicais. In: REUNIÓN DE LA RED INTERNACIONAL EVALUACIÓN DE PASTOS TROPICALES - AMAZÔNA, 1., 1990, Lima, Peru. Memórias... Cali: CIAT, v.2, 1990. p.1103-1108.

REYES, E.H.; CORREA, V.M.; CORREA, J.C. et al. Intervalo entre partos, duración de la lactacion y producción de leche en hato de doble propósito en Yucatán, México. Agrociência, v.35, p.699-705, 2001.

SANTANA, J.R.; PEREIRA, J.M. Sistema de produção de leite a pasto em Itajú do Colônia (BA). In: CONGRESSO NORDESTINO DE PRODUÇÃO ANIMAL, 1, Fortaleza, Ceará. Anais... Fortaleza: SNPA. 1998, p.165. 
BEZERRA, E.E.A. et al. Produção de leite e intervalo entre partos de um rebanho de vacas mestiças no Norte do Piauí. PUBVET, Londrina, V. 5, N. 1, Ed. 148, Art. 992, 2011.

SANTOS, F.A.P. Manipulação de fatores em sistemas de produção de leite. Glória Rural, v.2, n.22, p.24-25, 1999.

SILVA NETO, F.G. da, MAGALHÃES, J.A.; TAVARES, A.C. et al. Desempenho técnico-financeiro do sistema de produção de leite da Embrapa Rondônia. In: SEMINÁRIO REGIONAL AGRONÉGÓCIO LEITE, 1. Anais... Porto Velho, Embrapa Rondônia/SEAPS-RO/EMATERRO/SEBRAE-RO, 2001, p.97-100.

VETROMILA, M.A.M. Manejo e reprodução de fêmeas leiteiras. Sistemas de pecuária de leite: uma visão da região de clima temperado. Pelotas: Embrapa Clima Temperado, 2000. pg. 103-114.

VIANA, H.A. Desempenho de fêmeas $1 / 2$ sangue holandês $x$ zebu em Goiás. In: SIMPÓSIO NORDESTINO DE ALIMENTAÇÃO DE RUMINANTES, 2., 1988, Natal. Anais... Natal: EMPARN, 1888. p. 258.

XIMENES, L.J.F. Predição do lucro por mudança unitária nas características de bovinos leiteiros no semi-árido do Nordeste. Fortaleza: UFC, 2009. 46f. Tese (Doutorado em Zootecnia) - Universidade Federal do Ceará. 